\title{
Accelerating effects of blebbistatin on relaxation process of cell membrane permeabilized trachea and taenia cecum from guinea pig
}

\author{
Satoko MIHASHI, Yukisato ISHIDA and Masaru WATANABE \\ Department of Frontier Health Sciences, Graduate School of Human Health Sciences, Tokyo \\ Metropolitan University, 7-2-10 Higashiogu, Arakawa-ku, Tokyo 116-8551, Japan
}

Submitted January 15, 2020; accepted in final form March 12, 2020

\begin{abstract}
Blebbistatin, a potent inhibitor of myosin II, is known to suppress smooth muscle contraction without affecting myosin light chain phosphorylation level. In order to clarify the regulatory mechanisms of blebbistatin on phasic and tonic smooth muscles in detail, we examined the effects of blebbistatin on relaxation process by $\mathrm{Ca}^{2+}$ removal after $\mathrm{Ca}^{2+}$-induced contraction of $\beta$-escin skinned (cell membrane permeabilized) trachea and taenia cecum preparations from guinea pigs. Blebbistatin significantly suppressed the force during relaxation both in skinned trachea and taenia cecum. The data fitting analysis of the relaxation processes indicates that blebbistatin accelerates slow (latch-like) bridge dissociation.
\end{abstract}

Key words: blebbistatin, skinned preparation, relaxation, latch

\section{Introduction}

Blebbistatin, an inhibitor of myosin II found by Sellers et al. $(1,2)$, is known to inhibit not only myosin II ATPase activities of vertebrate striated muscle and non-muscle (2), but also vertebrate smooth muscle myosin (SMM) ATPase activity $(3,4)$. Also, blebbistatin at around $10 \mu \mathrm{M}$ inhibited the contraction of intact smooth muscle preparations and smooth muscle cell (3-6). Furthermore, we reported that blebbistatin inhibited the contraction of skinned (cell membrane permeabilized) taenia cecum (7) and trachea (8) from the guinea pig without affecting the phosphorylation level of myosin light chain (MLC).

To further analyze the blebbistatin effects on the regulation of actin-myosin interaction in smooth muscle in detail, we examined the effects of the agent on the relaxation processes, composed of fast and slow components, of skinned trachea and taenia cecum of the guinea pig. The slow force decay during relaxation by a $\mathrm{Ca}^{2+}$ removal from the medium in skinned smooth muscle is thought to reflect the "latch", originally reported and

Corresponding author: Masaru Watanabe, MD, PhD, Department of Frontier Health Sciences, Graduate School of Human Health Sciences, Tokyo Metropolitan University, 7-2-10 Higashiogu, Arakawa-ku, Tokyo 116-8551, Japan 
hypothesized by Dillon et al. (9), or the latch-like state of smooth muscle (10-13). In the present study, effects of blebbistatin on fast and slow (latch-like) cycling bridge are discussed by the kinetic analysis of relaxation processes of skinned trachea and taenia cecum.

A preliminary report of this study was reported as Proceedings of the 22nd annual meeting of Japan Society of Adaptation Medicine (14).

\section{Materials and Methods}

Animal experiments were performed at Tokyo Metropolitan University at Arakawa. All experimental procedures conformed to the "Guidelines for Proper Conduct of Animal Experiments" approved by the Science Council of Japan, and were carried out under the "Rules and Regulations of the Animal Studies Committee of Tokyo Metropolitan University". In addition, Tokyo Metropolitan University approved all procedures involving animals (A27-1, A28-1, A29-1, A30-20). Male Hartley guinea pigs weighing about $250 \mathrm{~g}$ were euthanized under deep anesthesia with pentobarbital (Somnopentyl, Kyoritsu Seiyaku Co., Tokyo, Japan). The trachea and the taenia cecum were removed, and immersed in a normal extracellular solution (NES; described below). The trachea and taenia cecum specimens were skinned (cell membarane permeabilized) with $200 \mu \mathrm{M}$ $\beta$-escin (Sigma, St. Louis, MO, USA), and destroyed sarcoplasmic reticulum with $20 \mu \mathrm{M} \mathrm{Ca}$ ionophore A23187 (Sigma) in Relaxing solution (with ATP) for 30 min, then kept in the $50 \%$ glycerol at $-20^{\circ} \mathrm{C}$ to prevent freezing of Relaxing solution (with ATP).

A small layer strip of trachea or taenia cecum (0.1-0.2 mm wide and $1.5-2.5 \mathrm{~mm}$ long) was prepared by cutting skinned specimen of tracheal cartilage or taenia cecum and stripping connective tissue from the specimen. The skinned preparation was attached to a pair of tungsten wires with silk thread monofilaments, one of which was connected to a force transducer (ULA-10GR, Minebea Mitsumi Inc., Kanagawa, Japan) to measure isometric tension (15). A bubble plate system with six wells $(0.135 \mathrm{ml}$ each) was used to change the solution quickly (16).

\section{Experimental procedure}

The skinned preparation was stretched in Relaxing solution (with ATP). After the passive tension reached a steady level (resting tension, up to $10 \mu \mathrm{N}$ ), the preparation was immersed in $\mathrm{Ca}^{2+}$-activating solution (with $10^{-5} \mathrm{M} \mathrm{Ca}^{2+}$ ) to elicit the maximal $\mathrm{Ca}^{2+}$-induced contraction. When the contractile force reached a maximal steady level, $\mathrm{Ca}^{2+}$ was quickly removed in relaxation process with Relaxing solution (with cytidine triphosphate; CTP) for $15 \mathrm{~min}$ in the absence or presence of various concentrations of blebbistain to avoid blebbistatin effects on any phosphorylation/dephosphorylation processes (7), since CTP is a substrate for myosin ATPase, but not for any other kinases $(17,18)$. For making the rigor conditions in the relaxation process, Rigor solution (without ATP or CTP) was used. In the control, $1 \%$ of dimethylsulfoxide (DMSO, Sigma) was added in Relaxing solution (with CTP) or Rigor solution (without ATP or CTP) as a vehicle control.

\section{Solutions and chemicals}

NES contained $150 \mathrm{mM} \mathrm{NaCl}, 4 \mathrm{mM} \mathrm{KCl}, 2 \mathrm{mM} \mathrm{CaCl}, 1 \mathrm{mM} \mathrm{MgCl}_{2}, 10 \mathrm{mM}$ glucose, $5 \mathrm{mM}$ 2-[4-(2-hydroxyethyl)-1-piperazinyl] ethanesulphonic acid (Nacalai Tesque, Kyoto, Japan), and $50 \mu \mathrm{U} / \mathrm{ml}$ insulin (Sigma), and pH was adjusted with Tris(hydroxymethyl) aminomethane (Tris; Nacalai Tesque) $/ \mathrm{H}_{2} \mathrm{O}$ to $\mathrm{pH} 7.40$ at $30{ }^{\circ} \mathrm{C}$. Artificial intracellular solutions for skinned preparations contained $0.85 \mathrm{mM} \mathrm{Mg}$ (methanesulfonate) $)_{2}$, $1 \mathrm{mM}$ MgATP (1.35 mM total ATP $\mathrm{Na}_{2}$, Roche, Indianapolis, IN, USA) or $1 \mathrm{mM} \mathrm{MgCTP} \mathrm{(1.35} \mathrm{mM} \mathrm{total} \mathrm{CTP-}$ 
Table 1. Major component of the artificial intracellular solutions (mM)

\begin{tabular}{lcccc}
\hline & $\mathrm{Mg}^{2+}$ & $\mathrm{Ca}^{2+}$ & Nucleotide & Creatine phosphate \\
\hline Relaxing solution with ATP & 1.0 & 0 & MgATP 1.0 & 20 \\
Relaxing solution with CTP & 1.0 & 0 & MgCTP 1.0 & 20 \\
Rigor solution & 1.0 & 0 & 0 & 0 \\
$\mathrm{Ca}^{2+}$-activatin solution & 1.0 & 0.01 & MgATP 1.0 & 20 \\
\hline
\end{tabular}

$\mathrm{Na}$, Sigma), $20 \mathrm{mM}$ creatine phosphate $\mathrm{Na}_{2}$ (CrP; Nacalai Tesque), $10 \mathrm{mM}$ etylene glycole-bis(2-aminoetyl) tetraacetic acid (EGTA; Nacalai Tesque). K(methanesulfonate) (Nacalai Tesque) was added to the solutions to keep the ionic strength at $200 \mathrm{mM}$, and $\mathrm{pH}$ was adjusted with $20 \mathrm{mM}$ 1,4-piperazinediethanesulophonic acid (PIPES; Nacalai Tesque) and $\mathrm{KOH}$ (Wako Pure Chemicals, Osaka, Japan) to 7.0 at $30{ }^{\circ} \mathrm{C}$, which were prepared according to the method of Horiuti (16). Relxaing solution (with CTP) contained $1 \mathrm{mM} \mathrm{MgCTP}$ instead of MgATP. $\mathrm{Ca}^{2+}$-activating solution (at $10^{-5.0} \mathrm{M}$ ) were prepared by mixing the CaEGTA solution containing $10 \mathrm{mM}$ EGTA and $9.64 \mathrm{mM} \mathrm{Ca}$ (methanesulfonate) $)_{2}$ with $1 \mu \mathrm{M}$ calmodulin (Wako Pure Chemicals) with the artificial intracellular solution. The apparent dissociation constant of $\mathrm{Ca}^{2+}$-EGTA was assumed to be $10^{-6.4} \mathrm{M}$. Contents of the Rigor solution (without ATP or CTP) were $0.85 \mathrm{mM} \mathrm{Mg}$ (methanesulfonate) ${ }_{2}, 10 \mathrm{mM}$ EGTA. $\mathrm{K}$ (methanesulfonate) was added to the solutions to keep the ionic strength at $200 \mathrm{mM}$, and pH was adjusted with $20 \mathrm{mM}$ PIPES and $\mathrm{KOH}$ to 7.0 at $30^{\circ} \mathrm{C}$. Blebbistatin (Toronto Research Chemicals Inc., North York, ON, Canada) was dissolved into DMSO. Major components of the artificial intracellular solutions were noted in Table 1.

\section{Data analysis of the mechanical properties}

The relative tension level of the skinned preparations during relaxation are expressed as below;

relative tension $=($ an observed tension - the basal tension $) /\left(\right.$ maximal tension of the $\mathrm{Ca}^{2+}$-induced contraction - the basal tension).

The relaxation process after the $\mathrm{Ca}^{2+}$-induced contraction was kinetically analyzed by data fitting to an equation (see below) using the program of Kaleida Graph (Synergy Software, Reading, PA, USA) using the Levenberg-Marquart algorithm;

Force $(\mathrm{t})=\operatorname{Force}(0) \times\left[\mathrm{e}^{(-\mathrm{t} / \mathrm{fast})}+A \times\left(1-\mathrm{e}^{(-\mathrm{t} / \mathrm{fast})}\right) \times\left(1-\mathrm{e}^{(-\mathrm{t} / \mathrm{s} \text { slow-attach })}\right) \times \mathrm{e}^{(-\mathrm{t} / \text { slow-detatch })}\right]$ Formula 1 where Force $(0), \mathrm{e}^{(-\mathrm{t} / \mathrm{f} \text { fast })}, 1-\mathrm{e}^{(-\mathrm{t} / \mathrm{f} \text { fast })}, A, 1-\mathrm{e}^{(-\mathrm{t} / \text { slow-attach }}$, and $\mathrm{e}^{(-\mathrm{t} / \mathrm{s} \text { slow-detatch })}$ denote a relative tension level of the test contraction in the absence of blebbistatin, the number of activated cross-bridges, the number of detached cross-bridges, the rate of re-attachment of the detached cross-bridges, the number of attached slow-cycling (latch-like) state, and the number of detached slow cycling state, respectively. See Discussion in detail.

\section{Statistical analysis}

The results are presented as the mean \pm S.E.M. Statistical hypotheses on the differences between means were tested with Student's $t$-test for paired samples unless noted otherwise. The null hypotheses were rejected when $P$ was less than 0.05 . 


\section{Results}

\section{Effects of blebbistain on the relaxation time course of skinned tracheal and taenia cecum muscle preparation}

When maximally contracting $\beta$-escin skinned muscle preparations of guinea pig trachea and taenia caecum with $10^{-5.0} \mathrm{M} \mathrm{Ca}^{2+}$ were exposed to Relaxing solution (with CTP) for $\mathrm{Ca}^{2+}$ removal, the mechanical force fell gradually with an initial fast phase followed by a slow phase, as typically shown in Fig. 1. In the trachea, the removal of $\mathrm{Ca}^{2+}$ elicited a rapid relaxation with a latency of less than a few seconds followd by a gradual relaxation during $900 \mathrm{sec}$ observation time (Fig. 1A). In the taenia, the removal of $\mathrm{Ca}^{2+}$ elicited a prompt relaxation, and the rate of relaxation was apparently bigger and the level of relaxation reached in the observation time was lower, when compared with those of the trachea (Fig. 1B). The presence of blebbistatin $(30 \mu \mathrm{M})$ apparently accelerated relaxations of the trachea and taenia, and the relative amount of relaxation was bigger in the taenia (more than $90 \%$ of the maximum tension) than in the trachea (about $80 \%$ ) in the presence of blebbistatin (Fig. 1A and B).

Figure 2 shows the statistical representation for the $\mathrm{Ca}^{2+}$ removal-induced relaxation processes of the trachea (Fig. 2A) and taenia (Fig. 2B) in the absence and presence of blebbistatin (10 or $30 \mu \mathrm{M})$. Apparently, the initial relaxation phase after removal of $\mathrm{Ca}^{2+}$ was slower in the trachea than in the taenia, and the relaxed level during $900 \mathrm{sec}$ was higher in the trachea than in the taenia. The presence of blebbistatin $(30 \mu \mathrm{M}$, but not $10 \mu \mathrm{M}$ ) in the relaxing solution significantly augmented the relaxation process of the trachea at time $>700 \mathrm{sec}$ after $\mathrm{Ca}^{2+}$-removal. In the taenia, blebbistatin 10 and $30 \mu \mathrm{M}$ significantly elicited the augmentation of relaxation; significant differences were observed at time $>300 \mathrm{sec}$ at $10 \mu \mathrm{M}$ and at time $>40 \mathrm{sec}$ after $\mathrm{Ca}^{2+}$-removal at $30 \mu \mathrm{M}$.

\section{Effects of blebbistatin on relaxation-process in the rigor condition}

Figure 3 shows the effects of blebbistatin on the relaxation process in the absence of nucleotide in Rigor solution (without ATP or CTP). In the rigor conditions, relaxation processes of the trachea and taenia after $\mathrm{Ca}^{2+}$-removal apparently impeded. Compared with the normal CTP-contained conditions, the initial phase of relaxation was inhibited both in the trachea and taenia. The terminal relaxation level in the rigor conditions

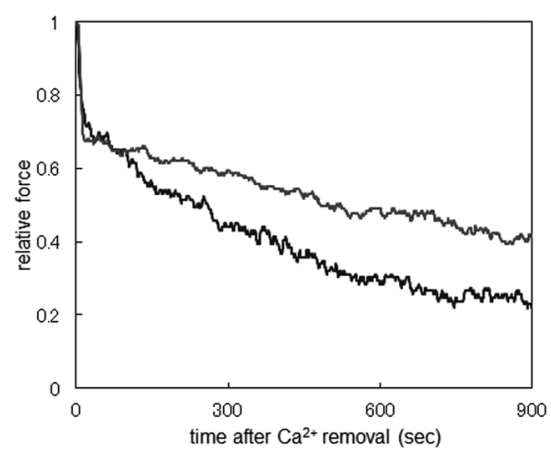

(A)

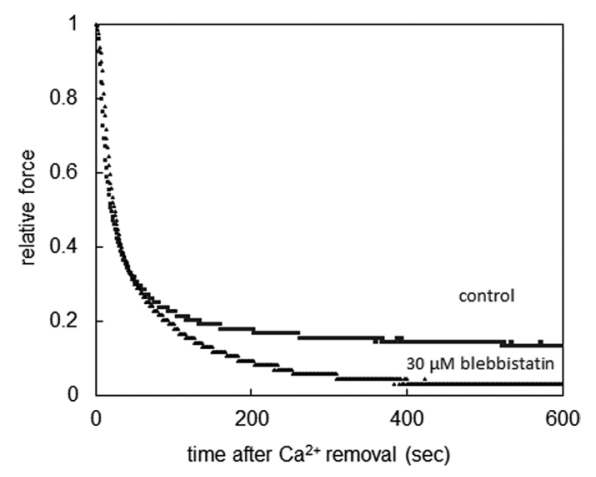

(B)

Fig. 1. Typical tension traces of relaxation process after $\mathrm{Ca}^{2+}$ removals of $\beta$-escin skinned (cell membrane peremiabilized) trachea (A) and taenia cecum (B) preparations in the Relaxing solution (with CTP) with or without blebbistatin at $30 \mu \mathrm{M}, 30.0 \pm 1.0^{\circ} \mathrm{C}$. Ordinate: Relative force normalized with the maximal tension level induced by $10^{-5.0} \mathrm{M} \mathrm{Ca}^{2+}$ promptly before the $\mathrm{Ca}^{2+}$ removal. Abscissa: Time in seonds after the $\mathrm{Ca}^{2+}$ removal. 
during observation time was not much different from the normal conditions in the trachea, but was much higher in the taenia.

The presence of blebbistatin $(10$ and $30 \mu \mathrm{M})$ did not have significant effects on the relaxation process in Rigor solution (without CTP) both in the skinned trachea (Fig. 3A) and taenia cecum (Fig. 3B).

\section{Data fitting analysis}

Relaxation processes of fast and slow phases in skinned preparations of trachea and taenia cecum were well fitted with the equation of Formula-1, considering with parameters of three constants for fast detaching ( $\tau$ fast-detach), slow attaching ( $\tau$ slow-attach) and slow detaching crossbridges ( $\tau$ slow-detach), and rate of re-

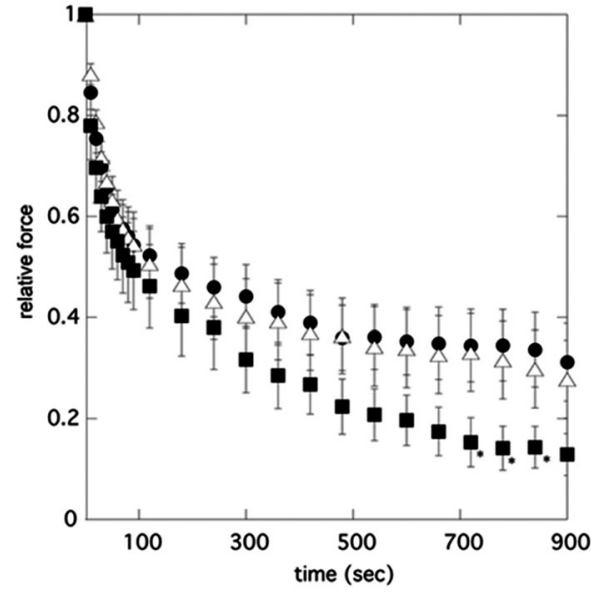

(A)

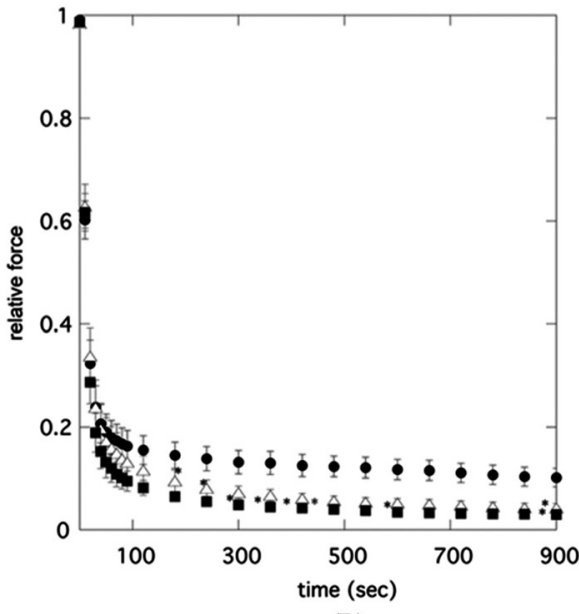

(B)

Fig. 2. Statistical representation for the effects of blebbistatin on the relaxation processes of $\beta$-escin skinned tracheal smooth muscle (A) and skinned taenia cecum (B) in the presence of CTP. Control (filled circles), and blebbistatin at $10 \mu \mathrm{M}$ (open triangles) and 30 $\mu \mathrm{M}$ (filled squares). Symbols and associated bars are means and \pm S.E.M., respectively, $\mathrm{n}=11$. *Significant difference of the force compared with that of control, where $P<0.05$.

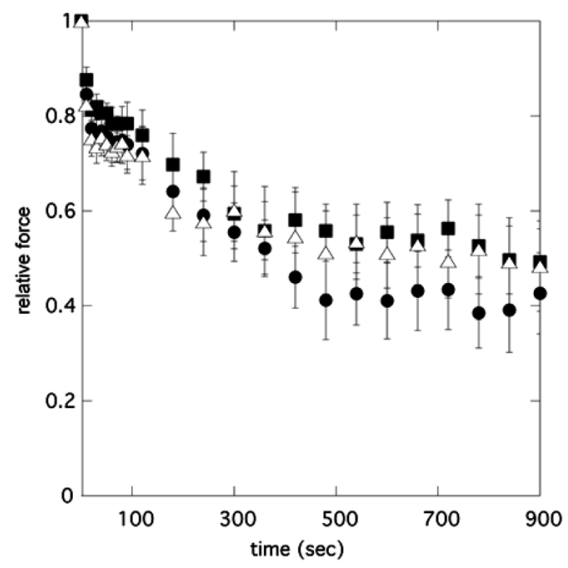

(A)

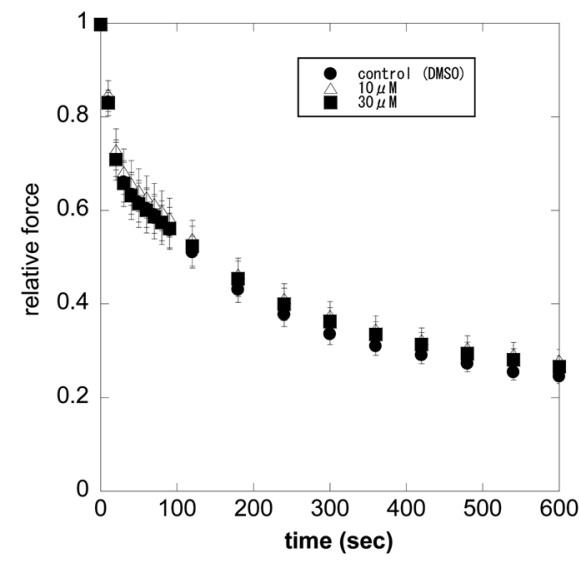

(B)

Fig. 3. Effects of blebbistatin on the relaxation processes of $\beta$-escin skinned tracheal smooth muscle (A) and skinned taenia cecum (B) in the absence of nucleotide (Rigor condition). Control (filled circles), and blebbistatin at $10 \mu \mathrm{M}$ (open triangles) and $30 \mu \mathrm{M}$ (filled squares). Symbols and associated bars are means and \pm S.E.M., respectively, $\mathrm{n}=11$. *Significant difference from the control $(P<0.05)$. 
attachment of detached crossbridges $(A)$ (see Materials and Methods).

In control conditions with CTP, $\tau$ fast-detach $(47.7 \mathrm{sec})$ and $A(0.618)$ of trachea were 2.5 and 3.6 times bigger than those of taenia, respectively, and other parameters were similar between trachea and taenia (Table 2), reflecting the slow and rapid relaxations of the trachea and taenia, respectively. The presence of blebbistatin $(30 \mu \mathrm{M})$ with CTP significantly reduced $\tau$ slow-detach to $2 / 5$ and $1 / 2$ of control in the trachea and taenia, respectively (Table 2), which represents the accerelation of detachment process in the slow (latch-like) bridges cycling. The presence of blebbistatin in Relaxing solution (with CTP) elicited a significant reduction in $A$ value by $1 / 2$ of control in the taenia, but a marginable and insignificant reduction in the trachea (Table 2).

Table 3 shows the effects of blebbistatin $(30 \mu \mathrm{M})$ on kinetic parameters for relaxation of skinned muscles in Rigor solution (without ATP or CTP). In the trachea, the presence of blebbistatin prolonged $\tau$ fast-detach 1.6 folds of control, just as much fold as that in Rexaxing solution (with CTP). In contrast to the reduction of

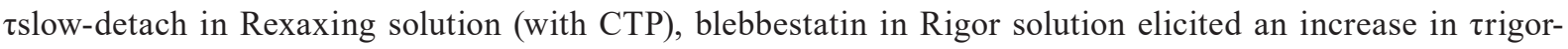
detach 2.4 folds of control in the trachea. Values of $\tau$ rigor-attach and $A$ of the trachea were not much affected by the presence of blebbistatin, being similar as in the normal solution. In the taenia exposed to Rigor solution, blebbistatin elicited marginal and insignificant effects on all parameters tested: small reduction in mean values of $\tau$ rigor-detach and a (both 0.8 folds of control). Briefly, the presence of blebbisttin in Rigor solution elicited the prolongation in $\tau$ rigor-detach in the trachea, but tended to marginally elicit the accerelation in $\tau$ rigor-detach and the inhibition in re-attachment of crossbridges in the taenia.

Table 2. Kinetic parameters of $\tau$ fast-detach, $\tau$ slow-attach, $\tau$ slow-detach, and $A$ obtained from relaxation processes of the skinned preparations of trachea and taeinia cecum of the guinea pig in Relaxing solution (with CTP) with or without blebbistatin $30 \mu \mathrm{M}$

\begin{tabular}{ccccc}
\hline & \multicolumn{2}{c}{ Trachea } & \multicolumn{2}{c}{ Taenia cecum } \\
\cline { 2 - 5 } & Control & $30 \mu \mathrm{M}$ & Control & $30 \mu \mathrm{M}$ \\
\hline$\tau$ fast-detach $(\mathrm{sec})$ & $47.7 \pm 5.56$ & $79.3 \pm 26.5$ & $19.0 \pm 2.28$ & $17.0 \pm 1.50$ \\
$\tau$ slow-attach $(\mathrm{sec})$ & $59.6 \pm 36.1$ & $51.9 \pm 14.8$ & $55.3 \pm 15.5$ & $67.0 \pm 36.4$ \\
$\tau$ slow-detach $(\mathrm{sec})$ & $1,830 \pm 413$ & $774 \pm 218^{*}$ & $2,000 \pm 343$ & $1,060 \pm 239^{*}$ \\
$A$ & $0.618 \pm 0.057$ & $0.536 \pm 0.097$ & $0.168 \pm 0.026$ & $0.092 \pm 0.018^{*}$ \\
\hline
\end{tabular}

Values represent mean \pm S.E.M. (trachea $\mathrm{n}=11$, taenia cecum $\mathrm{n}=8$ ). $* P<0.05$.

Parameters of $\tau$ fast-detach, $\tau$ slow-attach, $\tau$ slow-detach and $A$ represent the rate constants of fastly detaching, slowly attaching and slow detaching crossbridges, and the rate of re-attachment of detached crossbridges, in order.

Table 3. Effect of blebbistatin on $\tau$ fast-detach, $\tau$ rigor-attach, $\tau$ rigor-detach, and $A$ in the absence of nucleotide in Rigor solution

\begin{tabular}{ccccc}
\hline & \multicolumn{2}{c}{ Trachea } & \multicolumn{2}{c}{ Taenia cecum } \\
\cline { 2 - 5 } & Control & $30 \mu \mathrm{M}$ & Control & $30 \mu \mathrm{M}$ \\
\hline$\tau$ fast-detach (sec) & $78.0 \pm 13.1$ & $126 \pm 16.6$ & $35.2 \pm 4.53$ & $39.4 \pm 8.59$ \\
trigor-attach (sec) & $42.4 \pm 4.00$ & $46.3 \pm 8.15$ & $24.7 \pm 7.55$ & $34.2 \pm 9.16$ \\
trigor-detach (sec) & $1,500 \pm 380$ & $3,590 \pm 14.7^{*}$ & $1,250 \pm 161.6$ & $980 \pm 140$ \\
$A$ & $0.648 \pm 0.050$ & $0.526 \pm 0.089^{*}$ & $0.450 \pm 0.044$ & $0.381 \pm 0.070$ \\
\hline
\end{tabular}

Values represent mean \pm S.E.M. (trachea $\mathrm{n}=11$, taenia cecum $\mathrm{n}=8$ ). $* P<0.05$.

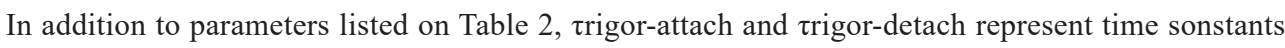
of attaching and detaching rigor-bridge in the rigor conditions. 


\section{Discussion}

The present study showed that in $\beta$-escin skinned tracheal and taenia cecum smooth muscle preparations from guinea pigs, blebbistatin significantly accelerated relaxation process by $\mathrm{Ca}^{2+}$ removal after the $\mathrm{Ca}^{2+}-$ induced active tension development.

Before discussing the mechanisms of the accelerating effects of blebbistatin on the relaxation, we will note the adequacy of data fitting of the regression analysis. We previously proposed that a portion of $\mathrm{Ca}^{2+}-$ calmodulin-activated fast crossbridges do not dissociate rapidly following dephosphorylation of myosin light chain by $\mathrm{Ca}^{2+}$ removal, but are transferred to latch-bridges $(12,13)$ that dissociate very slowly. Consequently, the observed time course of the force change during relaxation was well fitted with an equation that includes two time constants for the fast detaching crossbridges and the latch-bridges (11), as given below;

Force $_{(t)}=$ Force $_{(0)} \times\left[(1-A) \times \mathrm{e}^{(-t / \tau(\text { fast }))}+A \times \mathrm{e}^{(-t / \tau(\text { latch })}\right)-$ Formula 2

where $t$ is time after $\mathrm{Ca}^{2+}$ removal, $\tau$ (fast) and $\tau$ (latch) are time constants of the fast detaching crossbridges and the latch-bridges respectively, $A$ is the fraction of the crossbridges transferred from the fast detaching crossbridges to the latch-bridges, Force $_{(t)}$ is the relative force at $t \mathrm{sec}$ after the $\mathrm{Ca}^{2+}$ removal. Since the dissociation rate of fast detaching crossbridges is linearly related to the rate of MLC dephosphorylation, $\tau$ (fast) is expressed as a function of time constant of MLC dephosphorylation [ $\tau($ MLC-D)] as $\tau($ fast $)=k \times \tau($ MLC-D) -Formula 3,

where $\mathrm{k}$ is a constant of complex reactions other than MLC dephosphorylation during fast detaching crossbridges.

However, we observed that the initial force decay followed by a small force increment shortly, then a very slow force decrement was observed in some skinned preparations (data not shown), so Formula 2 is difficult to explain the observation. Therefore, we now propose that a number of detached fast crossbridges reattached then slowly detached described as Formula 1 to explain the small force increment after the initial force decay. Since the regression analysis using the Formula 1 fits the time course of the present data almost precisely, we suggest that the Formula 1 is adequate to explain the relaxation process of the skinned smooth muscle.

The regression analysis shows that acceleration of relaxation process by blebbistatin is due to accelerate detachment of slow cycling (latch-like) bridges, but not to alteration in detachment of the fast cycling crossbridges both in skinned trachea and taenia cecum (Table 2). Blebbistatin binds at the apex of the $50 \mathrm{kDa}$ cleft of the skeletal myosin head of myosin-ADP-Pi complex and interferes with the phosphate release process, resulting that the inhibitor blocks myosin in an actin-detached state, and therefore it prevents rigid actomyosin cross-linking in skeletal muscle myosin $(1,2)$. Also, the molecule stabilizes the helical order of myosin filaments of striated muscles (19). In smooth muscle, we previously found that blebbistatin suppressed the force development independent of $\mathrm{Ca}^{2+}$ sensitivity for the force and MLC phosphorylation level in $\beta$ escin skinned taenia cecum (7) and trachea (8), and conformational changes in SMM (7), and these results indicates direct inhibition of actin-myosin interaction through modulation of SMM ATPase activity and/or SMM structure by blebbistatin. Therefore, the present result that blebbistatin had little effects on detachment of fast cycling crossbridge ( $\tau$ fast-detach in Table 2 ) supports our previous conclusion $(7,8)$, since the detachment of the fast cycling crossbridge depends on the dephosphorylation of MLC (13, Formula 3$)$, and also the previous evidence that blebbistatin might not act after phosphate release from $\operatorname{SMM}(1,2)$.

Our present results also indicate that blebbistatin acts slow cycling (latch-like) bridges as accelerating dissociation ( $\tau$ slow-detach in Table 2). Blebbistatin is known to bind with neither nucleotide-binding pocket of myosin-head nor actin binding site, and causes a conformational changes of lever arm domain of myosin head 
by binding to MgADPPi bound state of myosin (20). Therefore, blebbistatin induced acceleration of slow cycling (latch-like) bridge dissociation might result from not only inhibiting myosin ATPase activity, but changes in myosin orientation by conformational change of myosin head. In fact, ATPase activity is much lower of slow cycling (latch) bridges than that of fast cycling crossbridges, indicating that contribution of SMM ATPase inhibition seems to be relatively little in blebbistatin induced acceleration of slow cycling (latch-like) bridge dissociation. Interestingly, blebbistatin decreased the rate of re-attachment (“ $A$ " in Table 2) only in skinned taenia cecum, but not in skinned trachea. Differences of factors such as cooperativity between trachea and taenia cecum may determine the rate " $A$ ", which contributes to the different susceptibility of blebbistatin effects on the slow cycling (latch-like) bridge formation. In particular, contractility of tracheal and colonic smooth muscle is characterized as "tonic" and "phasic", respectively (21), suggesting that the differences of regulatory mechanisms between "tonic" and "phasic" smooth muscle might contribute the differences of the blebbistatin effects. In other words, blebbistatin may be a tool for classifying smooth muscle into phasic and tonic muscles.

As shown in Fig. 3, $\mathrm{Ca}^{2+}$ removal caused a slow force decay even in the absence of nucleotides (rigor state). Our results support conclusions of previous studies that the axial motion of smooth muscle bound to actin upon dissociation of MgADP was not associated with (rigor) force generation (22), and MgADP release rate of SMM is about 20 times slower than that of skeletal myosin (22).

Blebbistatin had little effects on the force decay in the absence of nucleotide in Rigor solution (without ATP or CTP) in skinned taenia cecum, and this observation is consistent with binding characteristics of blebbistatin with myosin (1). On the other hand, in skinned trachea, the kinetic analysis suggests that the agent suppresses both formation and deformation of rigor-bridge (Table 3). Although difference of nucleotide release rate between skinned trachea and taenia cecum in Rigor solution (without ATP or CTP) causes the divergences of the results, further studies are necessary for the mechanisms of blebbistatin effects on smooth muscle in the absence of nucleotides.

It should be also noted that blebbistatin suppresses not only SMM activity, but also non-muscle myosin (NMM) activity in tracheal muscle, and the agent attenuates tracheal muscle contraction through inhibiting formation of membrane adhesome complexes which mediate force transmission and regulate cortical actin polymerization (23). In fact, blebbistatin inhibits translocation of protein kinase $\mathrm{C}$ (PKC) $\zeta$ to cell membrane through suppression of NMM activity in myotube (24). Therefore, blebbistatin-induced NMM inhibition modulates PKC activity which accelerate relaxation process in skinned smooth muscle, since PP2A inhibition suppresses contraction of basilar artery through PKC mediated MLC thiophosphorylation (25). However, as described in Materials and Methods, we measured the relaxation process using Relaxing solution (with CTP) to avoid blebbistatin effects on any phosphorylation/dephosphorylation processes (7), since CTP is a substrate for myosin ATPase, but not for any other kinases $(17,18)$. Thus, contribution of any phosphorylation/dephorphorylation processes during relaxation process in the present study seems to be negligible.

In conclusion, blebbistatin accelerates relaxation process of skinned smooth muscle by affecting slow cycling (latch-like) bridge formation and/or its dissociation. Since regulatory mechanisms of slow cycling (latch-like) bridge are still unclear, blebbistatin is a useful tool in investigating slow cycling (latch-like) bridge in detail.

\section{Conflict of Interest}

The authors declare that they have no conflict of interest. 


\section{Acknowledgment}

This study was supported in part by a Grant-in-Aid for Scientific Research from the Ministry of Education, Sciences, Sports and Culture of Japan (23500475; 2011-2015 to MW and 16K08500; 2016-2018 to MW).

\section{References}

1. Kovács M, Tóth J, Hetényi C, Málnási-Csizmadia A, Sellers JR. Mechanism of blebbistatin inhibition of myosin II. J Biol Chem. 2004; 279(34): 35557-63. [Medline] [CrossRef]

2. Limouze J, Straight AF, Mitchison T, Sellers JR. Specificity of blebbistatin, an inhibitor of myosin II. J Muscle Res Cell Motil. 2004; 25(4-5): 337-41. [Medline] [CrossRef]

3. Eddinger TJ, Meer DP, Miner AS, Meehl J, Rovner AS, Ratz PH. Potent inhibition of arterial smooth muscle tonic contractions by the selective myosin II inhibitor, blebbistatin. J Pharmacol Exp Ther. 2007; 320(2): 865-70. [Medline] [CrossRef]

4. Katayama T, Yoshiyama S, Tanaka H, Wang HH, Nakamura A, Kohama K. Blebbistatin inhibits sphingosylphosphorylcholine-induced contraction of collagen-gel fiber populated by vascular smooth-muscle cells. J Pharmacol Sci. 2006; 102(3): 339-42. [Medline] [CrossRef]

5. Ekman M, Fagher K, Wede M, Stakeberg K, Arner A. Decreased phosphatase activity, increased $\mathrm{Ca}^{2+}$ sensitivity, and myosin light chain phosphorylation in urinary bladder smooth muscle of newborn mice. J Gen Physiol. 2005; 125(2): 187-96. [Medline] [CrossRef]

6. Wang HH, Tanaka H, Qin X, Zhao T, Ye LH, Okagaki T, Katayama T, Nakamura A, Ishikawa R, Thatcher SE, Wright GL, Kohama K. Blebbistatin inhibits the chemotaxis of vascular smooth muscle cells by disrupting the myosin II-actin interaction. Am J Physiol Heart Circ Physiol. 2008; 294(5): H2060-8. [Medline] [CrossRef]

7. Watanabe M, Yumoto M, Tanaka H, Wang HH, Katayama T, Yoshiyama S, Black J, Thatcher SE, Kohama K. Blebbistatin, a myosin II inhibitor, suppresses contraction and disrupts contractile filaments organization of skinned taenia cecum from guinea pig. Am J Physiol Cell Physiol. 2010; 298(5): C1118-26. [Medline] [CrossRef]

8. Yumoto M, Watanabe M. Blebbistatin, a myosin II inhibitor, suppresses $\mathrm{Ca}^{2+}$-induced and "sensitized"contraction of skinned tracheal muscles from guinea pig. J Smooth Muscle Res. 2013; 49: 89-98. [Medline] [CrossRef]

9. Dillon PF, Aksoy MO, Driska SP, Murphy RA. Myosin phosphorylation and the cross-bridge cycle in arterial smooth muscle. Science. 1981; 211(4481): 495-7. [Medline] [CrossRef]

10. Kühn H, Tewes A, Gagelmann M, Güth K, Arner A, Rüegg JC. Temporal relationship between force, ATPase activity, and myosin phosphorylation during a contraction/relaxation cycle in a skinned smooth muscle. Pflügers Arch. 1990; 416(5): 512-8. [Medline] [CrossRef]

11. Albrecht K, Schneider A, Liebetrau C, Rüegg JC, Pfitzer G. Exogenous caldesmon promotes relaxation of guinea-pig skinned taenia coli smooth muscles: inhibition of cooperative reattachment of latch bridges? Pflugers Arch. 1997; 434(5): 534-42. [Medline] [CrossRef]

12. Yoshino Y, Sakurai W, Morimoto S, Watanabe M. Synthetic peptides of actin-tropomyosin binding region of troponin I and heat shock protein 20 modulate the relaxation process of skinned preparations of taenia caeci from guinea pig. Jpn J Physiol. 2005; 55(6): 373-8. [Medline] [CrossRef]

13. Hashimoto R, Yumoto M, Watanabe M, Konishi M, Haraoka J, Miki T. Differential effects of an expected actin-tropomyosin binding region of heat shock protein 20 on the relaxation in skinned carotid artery and taenia cecum from guinea pig. J Smooth Muscle Res. 2009; 45(1): 63-74. [Medline] [CrossRef]

14. Mihashi S, Watanabe M. Mechanisms of switching actin-myosin binding states which induce force 
maintenance in smooth muscle. Tekiouigaku. J Adapt Med. 2019; 22: 8-13 (in Japanese).

15. Watanabe M, Takano-Ohmuro H. Extensive skinning of cell membrane diminishes the force-inhibiting effect of okadaic acid on smooth muscles of guinea pig hepatic portal vein. Jpn J Physiol. 2002; 52(2): 141-7. [Medline] [CrossRef]

16. Horiuti K. Mechanism of contracture on cooling of caffeine-treated frog skeletal muscle fibres. J Physiol. 1988; 398: 131-48. [Medline] [CrossRef]

17. Cassidy P, Kerrick WG. Superprecipitation of gizzard actomyosin, and tension in gizzard muscle skinned fibers in the presence of nucleotides other than ATP. Biochim Biophys Acta. 1982; 705(1): 63-9. [Medline] [CrossRef]

18. Flockhart DA, Freist W, Hoppe J, Lincoln TM, Corbin JD. ATP analog specificity of cAMP-dependent protein kinase, cGMP-dependent protein kinase, and phosphorylase kinase. Eur J Biochem. 1984; 140(2): 289-95. [Medline] [CrossRef]

19. Zhao FQ, Padrón R, Craig R. Blebbistatin stabilizes the helical order of myosin filaments by promoting the switch 2 closed state. Biophys J. 2008; 95(7): 3322-9. [Medline] [CrossRef]

20. Takács B, Billington N, Gyimesi M, Kintses B, Málnási-Csizmadia A, Knight PJ, Kovács M. Myosin complexed with ADP and blebbistatin reversibly adopts a conformation resembling the start point of the working stroke. Proc Natl Acad Sci USA. 2010; 107(15): 6799-804. [Medline] [CrossRef]

21. Zhang WC, Peng YJ, Zhang GS, He WQ, Qiao YN, Dong YY, Gao YQ, Chen C, Zhang CH, Li W, Shen HH, Ning W, Kamm KE, Stull JT, Gao X, Zhu MS. Myosin light chain kinase is necessary for tonic airway smooth muscle contraction. J Biol Chem. 2010; 285(8): 5522-31. [Medline] [CrossRef]

22. Dantzig JA, Barsotti RJ, Manz S, Sweeney HL, Goldman YE. The ADP release step of the smooth muscle cross-bridge cycle is not directly associated with force generation. Biophys J. 1999; 77(1): 386-97. [Medline] [CrossRef]

23. Zhang W, Gunst SJ. Non-muscle (NM) myosin heavy chain phosphorylation regulates the formation of NM myosin filaments, adhesome assembly and smooth muscle contraction. J Physiol. 2017; 595(13): 4279-300. [Medline] [CrossRef]

24. Saito T, Okada S, Shimoda Y, Tagaya Y, Osaki A, Yamada E, Shibusawa R, Nakajima Y, Ozawa A, Satoh T, Mori M, Yamada M. APPL1 promotes glucose uptake in response to mechanical stretch via the PKCל-non-muscle myosin IIa pathway in C2C12 myotubes. Cell Signal. 2016; 28(11): 1694-702. [Medline] [CrossRef]

25. Obara K, Ito Y, Shimada H, Nakayama K. The relaxant effect of okadaic acid on canine basilar artery involves activation of PKC $\alpha$ and phosphorylation of the myosin light chain at Thr-9. Eur J Pharmacol. 2008; 598(1-3): 87-93. [Medline] [CrossRef] 